\title{
Author Correction: Clopidogrel as a donor probe and thioenol derivatives as flexible promoieties for enabling $\mathrm{H}_{2} \mathrm{~S}$ biomedicine
}

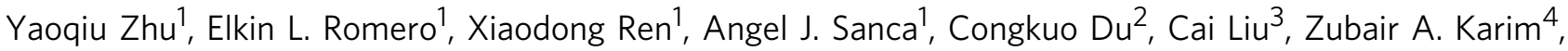 \\ Fatima Z. Alshbool ${ }^{4}$, Fadi T. Khasawneh ${ }^{4}$, Jiang Zhou (1) ${ }^{5}$, Dafang Zhong ${ }^{3} \&$ Bin Geng $^{2}$
}

Correction to: Nature Communications ; https://doi.org/10.1038/s41467-018-06373-0; published online: 27 September 2018

The original version of this article contained an error in the spelling of the author Bin Geng, which was incorrectly given as Bing Geng. This has been corrected in both the PDF and HTML versions of the article.

Published online: 10 October 2018

\begin{abstract}
(c) Open Access This article is licensed under a Creative Commons Attribution 4.0 International License, which permits use, sharing, adaptation, distribution and reproduction in any medium or format, as long as you give appropriate credit to the original author(s) and the source, provide a link to the Creative Commons license, and indicate if changes were made. The images or other third party material in this article are included in the article's Creative Commons license, unless indicated otherwise in a credit line to the material. If material is not included in the article's Creative Commons license and your intended use is not permitted by statutory regulation or exceeds the permitted use, you will need to obtain permission directly from the copyright holder. To view a copy of this license, visit http://creativecommons.org/licenses/by/4.0/.
\end{abstract}

(C) The Author(s) 2018

\footnotetext{
${ }^{1}$ Department of Chemistry and Biochemistry, Border Biomedical Research Center, The University of Texas at El Paso, El Paso, TX 79968, USA. ${ }^{2}$ Hypertension Center, Fuwai Hospital, CAMS-PUMC, State Key Laboratory of Cardiovascular Disease, Beijing 102300, China. ${ }^{3}$ State Key Laboratory of Drug Research, Shanghai Institute of Materia Medica, Chinese Academy of Sciences, 501 Haike Road, Shanghai 201203, China. ${ }^{4}$ Department of Pharmaceutical Sciences, School of Pharmacy, The University of Texas at El Paso, El Paso, TX 79902, USA. ${ }^{5}$ Analytical Instrumentation Center, College of Chemistry and Molecular Engineering, Peking University, Beijing 100871, China. Correspondence and requests for materials should be addressed to Y.Z. (email: yzhu2@utep.edu)
} 